\title{
Basic Income Advocacy in Canada: Multiple Streams, Experiments and the Road Ahead
}

\section{Sid Frankel}

This chapter discusses three aspects of basic income advocacy in Canada. First, the multiple streams framework of policymaking (Kingdon 2011) is used to assess the status of basic income on Canadian policy agendas. Second, basic income experimentation has been a prominent strategy for Canadian basic income advocates; but a basic income policy has never come to fruition in Canada. The second section discusses some approaches that might increase the probability that basic income experiments result in full-scale implementation of basic income policies. Third, some possible approaches for basic income advocacy are described and analyzed.

\section{Multiple Streams Framework}

The multiple streams framework is an expansion of traditional stage theories of policymaking (Thurber 2011, vii-xi) that involves describing an interactive set of forces that drive the agenda-setting and alternative

S. Frankel ( $₫)$

University of Manitoba, Winnipeg, MB, Canada

e-mail: Sid.Frankel@umanitoba.ca

(C) The Author(s) 2020

R. K. Caputo and L. Liu (eds.), Political Activism and

Basic Income Guarantee, Exploring the Basic Income Guarantee, https://doi.org/10.1007/978-3-030-43904-0_8 
selection stages of the policy process. This framework has been highly influential (Rawat and Morris 2016, 608-638) and has been described by John $(1998,173)$ as closest to "an adequate theory of public policy." Kingdon developed the framework to explain policymaking in the United States; but it has been applied to the policymaking machinery in many countries, including Canada (Henstra 2010), and international comparative policymaking research (Béland and Howlett 2016).

Kingdon (2011) describes the agenda-setting stage as resulting in a list of problems to which government officials and their associates outside government are paying serious attention at a particular point in time. This list is a subset of all conceivable problems or subjects to which officials could be paying attention, and the agenda-setting stage focuses on the actors, forces and processes that result in narrowing the list of all conceivable problems to an agenda. This government agenda is further narrowed to a decision agenda, the list of subjects that are the focus of active decision-making.

Alternatives or alternative policy solutions are the set of alternate policies or policy modifications thought to solve problems on the decision agenda. A range of conceivable alternatives using various policy levers is available to intervene in any problem. The alternative selection phase involves narrowing this range to a set of alternatives to be more seriously considered, and eventually to an alternative solution which is selected.

In important respects, the multiple streams model is an adaptation of the garbage can model of organization choice (Cohen et al. 1972). According to this model, decision-making is not considered to be a comprehensive rational process, but rather a garbage can into which participants who drift in and out of decisions dump largely unrelated problems and solutions (Zahariadis 2019, 65-92).

Kingdon adopted the garbage can model assumption that decisions are made under conditions of ambiguity (Herweg and Zahariadis 2017). This ambiguity flows from three factors: problematic preferences, fluid participation involving many actors and unclear technology for problem solution (Smith 2018). Various actors' preferences are often problematic because they are unclear, ambivalent, fluid and sometimes even contradictory. Preferences may shift as circumstances change. Fluid participation relates to changes in both the decision-making body and variations in the levels of interest and involvement of various decision makers and decision support actors. Unclear technology relates to the processes whereby the government department or agency converts resource inputs into policy 
and program outputs. Decision makers may be unaware of or organizational norms may not clearly specify which officials are responsible to process various decisions and to enact the various activities of the implementation process.

Against this background, Kingdon organizes the processes that drive agenda setting and alternative selection into three independent and interdependent streams that interact to produce windows of opportunity (Béland and Howlett 2016). The problem stream is filled with conditions that are constructed as problematic and appropriate for state intervention by the public and policymakers. Problems come to attention through interpretation of indicators of various outcomes collected by governments or non-government policy organizations, focusing events and feedback related to program operations and outputs. Indicators may be the result of regular monitoring or special studies, and if a change (or sometimes, persistence) in indicators is constructed as problematic according to belief and value criteria, the referent condition may be constructed as a public policy problem.

Focusing events, such as crises and disasters, can sometimes bring attention to conditions that lead to their interpretation as public policy problems. This is especially likely when attention is reinforced by the media and policy advocates. Formal and informal feedback from existing programs can lead to the discovery of conditions that are constructed as problems requiring policy attention.

The policy stream is composed of a primeval soup of competing alternative solutions and proposals emergent from policy communities composed of government officials, political staff, academics and researchers from think tanks and civil society organizations who specialize in a particular problem area. In this competitive process, advocates for various proposals attempt to soften up policy communities and the public to establish a favorable environment for the proposal they favor. In establishing the policy short list, and eventually the selected alternative, criteria of technical and political feasibility, congruence with the values of policymakers and cost are generally invoked.

The political stream is composed of factors, which influence the body politic. Key factors include national mood, pressure group campaigns and turnover of legislative or administrative personnel.

When the three streams are coupled or joined at a particular point in time, an opportunity for policy change occurs. Kingdon (2011) refers to this as a policy window and defines it as a fleeting moment for advocates 
to push attention to a problem and/or adoption of a proposal. The opening of windows can be catalyzed by compelling events advancing a condition in the problem stream or political or senior administrative change in the political stream.

Beyond these processes, policy entrepreneurs are key individual or organizational actors who invest their resources (time, energy, reputations and sometimes money) in achieving a particular policy outcome. They play a key role in opening policy windows by linking or coupling policy problems with policy solutions in the context of political opportunity (Béland and Howlett 2016). Policy entrepreneurs are more than policy advocates. They are power brokers and practitioners of political manipulation (Zahariadis 2019). Entrepreneurs' success is dependent upon the level of their access to decision makers, the resources that they are able and willing to expend and their skill in using manipulative strategies (Smith 2018).

\section{Multiple Streams and Basic Income Policy Advocacy in Canada}

The multiple streams framework will now be applied to the Canadian context. In Canada, a basic income might be implemented by the federal government or by any of the ten provincial or three territorial governments, or, ideally, through some cooperative arrangement between the federal and provincial and territorial governments. Since a universal basic income has never been implemented, anywhere in Canada it is clear that either a policy window has never opened or that policy advocates and policy entrepreneurs have been unable to take advantage of the opening.

\section{The Problem Stream}

Beginning with the problem stream, it seems clear that basic income cannot be classified as a policy problem in need of management, but as one of a number of alternative solutions. From the multiple streams perspective, basic income must be successfully linked or coupled with a problematic condition that is on the decision agenda of policymakers. Without this coupling, and the presence of favorable conditions in the political stream, a policy window cannot be opened. 
But, to which policy problem or problems can basic income be linked as a solution? Basic income has been identified as at least a partial solution for a large range of problems, including the increased presence of precarious work in the Canadian labor market (Lewchuk 2018, 3344 ), increasing unemployment and underemployment due to technological change (Kaplan 2015), enhancing ecological sustainability (Marston 2016), poverty reduction, decreasing economic inequality, labor market flexibility, low wage subsidization, welfare state downsizing or abolition, improvement in the position of women, persons with disabilities and ethnocultural minorities, furtherance of social justice, citizenship enhancement and democratic development (Pateman and Murray 2012; Frankel and Mulvale 2014).

In one sense, it might seem advantageous in terms of policy adoption that basic income can be linked as a solution to so many problems. After all, this might mean that basic income would yield a broad range of benefits. Nevertheless, this characteristic may be problematic in terms of the process of agenda setting for several reasons. First, many of the problem constructions described above flow from divergent and sometimes contradictory frames of reference. Second, this range of problems means that political and bureaucratic decision makers from a large group of government departments and agencies would have to be involved in agenda setting and alternative selection. This might be unmanageable. Third, policy communities involving specialists from a diverse range of areas would be difficult to organize into a coherent coalition or network.

However, in Canada, the primary problem to which basic income has been linked is poverty reduction, with reductions in inequality, management of a labor market with many precarious jobs and enhancement of environmental sustainability often cited as secondary problems that can be ameliorated through basic income (Mulvale and Frankel 2016).

In addition, feedback related to the limitations of last resort, highly conditional social assistance programs is often described as a policy problem that implementation of a basic income scheme could solve, largely through replacing or decreasing the need for these highly residual and selective income transfers (Forget 2018; Frankel and Mulvale 2014). Limitations of social assistance identified include inadequate benefits (Tweddle and Aldridge 2019), narrow eligibility criteria based on reason for need rather than fact of need, high levels of conditionality related to employment seeking and expenditure, high tax back rates on earned 
income, and stigmatization (Calnitsky 2016), which impairs social integration. This generates the need for an expensive bureaucracy to determine eligibility and monitor for compliance with conditions (Forget 2018).

\section{The Policy Stream}

The policy stream has been described as a chaotic primeval soup of competing solutions. In this highly competitive environment, advocacy for basic income in Canada has been compromised by three factors. First, there is fundamental disagreement about the set of characteristics that are necessary to define a policy scheme as a basic income (Smith-Carrier and Green 2017). For example, some dismiss negative income tax schemes as violating the universality criterion of Van Parijs' $(2004,7)$ original definition of basic income as an "income paid by a political community to all its members on an individual basis, without means test or work requirement." Others see a negative income tax as a form of basic income. Forget (2018) sees the only defining criterion for a basic income as unconditionally, or the absence of a requirement for labor market activity.

A second compromising factor is that not only must basic income compete against other proposed policy alternatives, but also any one basic income proposal must compete with many others. As Forget (2018) notes, these proposals vary considerably regarding the guarantee levels provided, the tax back rate and what, if any, other welfare state programs are replaced.

A third compromising factor is that some specialists (Kesselman 2014; Green et al. 2017) have labeled basic income as having an inherently prohibitive cost. As noted above, cost is one of the key criteria for selection of a particular alternative from the set of available solutions.

An additional consideration is that policy advocates have used the strategy of pointing to existing grants and income-tested benefits as forms of basic income (Mulvale and Frankel 2019). For example, a recent report from the Canadian Centre for Economic Analysis (2019) refers to the Canada Child Benefit (an income-tested child income transfer) as a basic income guarantee for Canadian families with children. The logic of the strategy involves attaching the basic income concept to policies that have broad support and benefit many Canadians. The problem is that this approach may siphon public and policymaker support away from a basic income because advocates are telling them that we already have one. 


\section{The Political Stream}

Limited polling data (Ipsos 2017) show that Canadians are ambivalent about basic income, or at least they were in 2017. Based on a national sample of $1,000,44 \%$ favored and $31 \%$ opposed the proposal that "the government should pay all residents in Canada a basic income in the form of free and unconditional money in addition to any income received from elsewhere." Although 61\% thought that basic income would help alleviate poverty and free up family time and $50 \%$ believed that basic income would help people become more involved in their communities, $60 \%$ thought that basic income would make people reliant on the state and avoid jobseeking. In addition, $52 \%$ of respondents thought that financing a basic income would increase taxation to unaffordable levels. A more recent web-based survey (Reinhart, 2019) of 3,049 respondents conducted in May and June 2019 asked a question based on a narrower conception of the purpose of basic income. This question was "Do you support or not support a universal basic income as a way to help people in Canada who lose their jobs because of advances in artificial intelligence?" Seventy-five percent indicated support, with support stronger among women (77\%) than among men $(72 \%)$. Support was also negatively associated with age and educational attainment. However, only $49 \%$ of respondents would be willing to pay higher taxes to fund such a basic income program. Given the differences in questions between the two surveys, it is difficult to determine if support among Canadians for basic income grew substantially over the two-year interval between them. It is, however, a significant concern about high taxation makes it clear that Canadian governments do not seem to be facing strong public pressure to implement a basic income.

Two civil society organizations are engaged in conducting public pressure campaigns in support of basic income in Canada. The longest standing is the Basic Income Canada Network (Mulvale and Frankel 2016), founded in 2008. It is connected to a network of provincial, territorial and local organizations throughout the country. A strong activist volunteer board of directors that includes academics, entrepreneurs, experienced policy analysts and activists heads the organization. However, its public advocacy capacity is limited by lack of financial resources. In 2018-2019, its revenues were somewhat less than $\$ 84,000$ (Basic Income Canada Network 2019b). Newer on the scene is UBI Works, recently founded by a group of Canadian entrepreneurs, with the mission of providing evidence to the public to encourage it to recognize basic income as an economic 
need and economic opportunity, with the goal of seeing a universal basic income implemented in Canada (UBI Works, n.d.).

The major change in the political stream that might have created a favorable environment for the introduction of a basic income was the replacement of the federal Conservative government with a Liberal government (under Prime Minister Justin Trudeau) in 2015. The Liberal Party membership had passed several motions in support of basic income (Liberal Party of Canada 2014, 2016, 2018). The party's election platform included a promise to establish a poverty reduction strategy, which came to fruition in August 2018 (Canada 2018). The development of this strategy occurred under the direction of Jean-Yves Duclos, an academic economist appointed as Minister of Families, Children and Social Development. He had extensively studied the economics of basic income, sometimes viewing it more favorably (Duclos 2007) than others (Clavet et al. 2012).

In December 2018, Duclos gave an interview to the National Post (Press 2018), a prominent Canadian daily newspaper, in which he argued that the Canada Child Benefit and other measures already constituted a basic income for Canadian families with children. He went on to say:

Whether this is going to be enhanced eventually to a broader guaranteed minimum income for all Canadians, including those without children that are not currently covered by a guaranteed minimum income at the federal level, I believe the answer is yes. At some point, there will be a universal guaranteed minimum income in Canada for all Canadians.

Presciently, he added "One day we will get there too, but that day has not yet arrived." Further discussion of basic income did not occur in the 2019 federal election, and the re-elected Liberal government has not initiated it.

In the political stream, Canadian policymakers are faced with an ambivalent public and civil society organization with limited capacity, although this may be expanding.

\section{Policy Window}

The most likely time when a policy window might have opened for a national basic income in Canada was from 2015 to 2019, the period 
in which Opportunity for All: Canada's First Poverty Reduction Strategy (Canada 2018) was developed. During this period, poverty was sufficiently prominent in the problem stream and there was at least some party and cabinet support in the political stream. As described above, various basic income proposals were available in the policy stream. One example was a 2016 proposal developed by Robin Boadway, a prominent Queens University public sector economist, and colleagues (Boadway et al. 2016).

However, the opening of this window may have been prevented by the political strategy of the Trudeau Liberal government in relation to controlling expectations and expenditures, while demonstrating success in the reduction of poverty. Thus, the strategy established an official poverty measure, set targets and timelines, committed to poverty reduction legislation and established an advisory committee. It did not, however, include any policies, programs or expenditure commitments to reach the targets (Robson 2018). Therefore, there was no opportunity for a policy window to open because the poverty reduction strategy avoided a policy agenda. The emergence of the Coronavirus pandemic, and specifically the need for stimulus to support aggregate demand and income replacement for households which have lost employment and self-employment earnings, may have opened another policy window for basic income as a broader consensus than usual has emerged in support of it as a solution to the economic effects of the pandemic (Toronto Star 2020). In this context, policy entrepreneurs and members of policy communities have advocated for basic income in the media (Frankel 2020; Forget and Segal 2020), but sometimes only as a temporary measure during the pandemic and recovery (Boessenkool 2020). Fifty Canadian senators, almost half of the chamber, have written to the prime minister calling for a basic income (Eggleton and Segal 2020), but the prime minister has rejected basic income in favor of targetted policies which help those who need it most (Wright 2020). In addition, he disputes the views that basic income is less complex than targetted approaches, and that it can deliver benefits more quickly. However, pressure continues to mount to implement a basic income.

\section{Policy Entrepreneurs}

As described above, policy entrepreneurs are power brokers and political manipulators who must have access to policymakers, be able to martial resources and to implement political strategies skillfully in order to be successful. One long-standing Canadian policy entrepreneur for basic income 
is Hugh Segal (2019). He likely possesses sufficient political skill, given his employment as chief of staff to a former prime minister and associate cabinet secretary in the Ontario government, as well as his appointment as a senator. Given his prominence, and the fact that he was appointed to the Senate by Liberal Prime Minister Paul Martin and was appointed by Ontario Liberal premier Kathleen Wynne to prepare a discussion paper on Ontario's basic income pilot (Segal 2016), Segal likely has access to Liberal policymakers. He also has expended extensive reputational resources and displayed persistent energy in advocating for basic income. Beyond this, he has extensive connections to academic specialists because he has held positions with several Canadian universities.

Other policy entrepreneurs may be arising through the involvement of corporate leaders and entrepreneurs, especially from the high technology sector, involved on the board of Basic Income Canada Network and in the leadership and advisory committees of UBI Works. They see the disemployment effects of automation firsthand, construct basic income as a necessary solution and have access to and have committed significant resources to basic income advocacy. They also likely possess some level of political skill, given their roles as chief executive officers of corporations in relating to governments.

\section{Lessons from the Multiple Stream Analysis}

Although basic income has not yet reached the policy agenda, this analysis based on the multiple streams framework suggests several lessons to further basic income political advocacy in Canada, and by extension, elsewhere. The first is that advocates must remain highly vigilant for the opportunities presented by the opening of a policy window. According to the framework, a window may open unexpectedly due to changes in the political stream or a problem available for coupling entering the decision agenda. Once open advocates must respond quickly because the window may close because of changes in political circumstances or alternatives other than basic income being successfully coupled with the available problem. This implies that basic income policy communities and networks must be well organized and sufficiently resourced to take swift action.

Second, policy advocates must make difficult strategic choices in terms of how many and with which problematic conditions to couple basic income, especially in the period before policy windows are open. There are four main considerations, and they may imply contradictory actions. 
One is that basic income must be linked to problems for which the logic of basic income as a solution can be easily articulated and demonstrated. Ideally, some empirical and/or logical evidence for a causal connection should be available. Second, in terms of increasing public support, it may be useful to link basic income to as many problems as possible so that many segments of the public have a stake in placing basic income on the government agenda. Third, in order to facilitate the organization of wellintegrated policy communities and networks of specialists, it may be best to couple basic income with fewer problems and to select those problems that are relevant to the same or closely related academic specialties. Finally, in terms of targeting decision makers for advocacy, it may be useful to select fewer problems for coupling and to choose those managed by the same government department or agency. This will avoid both rivalry between units and lack of clarity about which unit is responsible. Advocates must balance these considerations based on which seems most crucial at a particular point in time.

A third lesson from the multiple streams analysis is that advocates and policy communities and networks must develop as much consensus as possible about the definition of basic income and, ideally, about a particular basic income proposal to put forward. This may be difficult to achieve; but it will likely enhance the position of basic income in the policy stream.

A final lesson is that basic income advocates should carefully develop cost estimates to attach to their proposals to counteract the contention that basic income is unaffordable by its very nature. This is especially necessary because opposing specialists often present unrealistically high estimates (Pereira 2017). The estimates prepared by basic income advocates should derive net costs after subtracting savings in other income support programs because of implementation of a basic income and decreases in health care, social service and criminal justice costs related to reductions in poverty (National Academies of Sciences, Engineering, and Medicine 2019). In order to meet the feasibility criterion, sources of financing should be identified. Beyond this, costs should be linked to outcomes in order to frame the financial commitment as an investment rather than a cost.

\section{BASIC INCOME EXPERIMENTATION}

Basic income proposals can take at least four forms in terms of their implementation, including full implementation (Caputo 2014), pilot 
studies to test the performance of administrative and delivery systems (Fraser and Galinsky 2010), incremental changes of existing programs to evolve toward a basic income (Offe 2001), and experiments and quasiexperiments to establish the effects of basic income interventions (Shadish et al. 2002). Each of these forms makes demands of different levels of gravity upon decision makers. Full implementation makes the most serious demands as decision makers are being asked to commit to the full costs of planning, implementing and operating the program, as well as exposing themselves to the political risks of implementation failures. Pilot studies ameliorate implementation failure risks and delay full operational costs, but imply eventual full implementation. An incremental approach decreases visibility, risk and cost in any particular year. Furthermore, it does not imply commitment to any particular eventual outcome, as small changes are often reversible. Experiments and quasi-experiments may be costly, but not as costly as full implementation. They also allow policymakers to avoid decisions until experimental evidence is available.

Advocates must take account of these gradations in decision gravity in formulating their proposals. They must calibrate the level of demand being made with the readiness of policymakers to commit to particular levels of cost and risk. One approach used several times in Canada has been that of advocates supporting experimentation as a means to demonstrate the cost and benefits of a basic income scheme in a manner that might attract public support and enhance political feasibility for policymakers. This also provides opportunities for policy learning (McLaughlin 1987).

\section{History of Basic Income Experimentation in Canada}

The first example is the Mincome experiment, which took place in the province of Manitoba between 1974 and 1979 based on an agreement between the federal government and the government of Manitoba (Mulvale and Frankel 2016). The focus of the experiment was to assess the labor supply effect of a basic income using a controlled randomized experimental design involving 1300 families from Winnipeg and rural Manitoba (Simpson et al. 2017). The design of the experiment involved random assignment to eight conditions based on three variations in guarantee level and three variations in tax rate or a control group. A tenth variation involving the highest guarantee level and lowest tax rate was deemed too expensive to implement. In addition, a saturation site was 
developed in the Town of Dauphin and the surrounding rural area, where enrollment in a single scheme was available to all who were eligible based on an income test. It was meant to study the effects of basic income in a context similar to full implementation, including community-wide and labor market effects. These data have also been used by Forget (2011), in a quasi-experimental design to assess the health and educational effects of a basic income.

By 1979, the project was prematurely cancelled. This was based on concerns about cost (Simpson et al. 2017) and changing political priorities due to changes in Canada's economic situation (Forget 2011). Another factor was the changes in decision makers at both the federal and provincial governments. In Manitoba, a Conservative government replaced the social democratic New Democratic government and in Ottawa a Conservative government replaced the Liberal government.

It took some time for findings to become available because of the abrupt and unplanned end of the experiment. However, when they did arrive they were quite positive. For example, Hum and Simpson (1993) used the Winnipeg sample to estimate labor supply effects and found only moderate decreases of $1 \%$ for men, $3 \%$ for wives and 5\% for unmarried women. Using the Dauphin saturation site, Forget (2011) used a combination of hard matching and propensity score matching to develop a comparison group composed of three individuals for every Dauphin subject. Her statistically controlled analysis demonstrated an $8.5 \%$ decrease in hospitalization rates, and especially those related to accidents, injuries, and mental health diagnoses during the Mincome period. She also found a decrease in physician claims related to mental health diagnoses. In addition, Forget used aggregate education data to study the likelihood of the movement of tenth grade students to grade eleven and of eleventh grade students to grade twelve. She compared Dauphin with other rural jurisdictions and with urban jurisdictions. During the experiment, Dauphin students had been the most likely to continue, when before the experiment they were less likely to continue than their urban counterparts were and about as likely as their rural counterparts were. The effect attenuated shortly after the experiment.

At the beginning of the Mincome experiment, it was generally accepted that it would be the prototype for a universal basic income scheme like Canada's universal healthcare program (Forget 2011). But, despite arguably positive results, this has not occurred. Offe's (2001) contention 
that no basic income experiment has ever resulted in full-scale implementation of a basic income continues to be valid.

The second example in the Canadian context is the announcement of a basic income pilot by the Liberal government in Ontario in 2017 (Ontario 2017). The pilot included 4,000 low-income participants in three sites and guaranteed provision of unconditional benefits well above social assistance or disability payments for three years. The tax rate on earned income was $50 \%$. The pilot was to assess a broad range of outcomes, including mental and physical health status, housing conditions and educational enrollment, as well as labor market participation (Segal 2016).

The Liberal government was defeated in 2018 and replaced by a Conservative government. Within two months of its election, it cancelled the pilot despite promising not to do so in the election campaign, to the accompaniment of strong condemnation from policy advocates (Mulvale and Frankel 2019). The new government claimed that the program "didn't work," although the authorities did not fund a follow-up survey to prove otherwise (Lindeman 2019). Basic Income Canada Network (2019a) published a survey of 424 pilot program recipients in February 2019 , finding improved health, well-being, food security, social connection, education and employment among recipients. These findings are confirmed in an interview-based research study (Hamilton and Mulvale 2019) and in a survey and interview study of participants in one of the pilot sites (Ferdosi et al. 2020).

The cancellation of the pilot was attacked by the trial recipients, Ontario Coalition Against Poverty, Hamilton Roundtable for Poverty Reduction and other anti-poverty advocates, who fear deeper cuts in social policy provision in other areas (CBC News 2018). 120 Canadian CEOs and business owners have signed their support for continuing the pilot. ${ }^{l}$ Former Liberal premier, Kathleen Wynne, also attacked the Conservative government for abandoning the pilot, but also regretted not having introduced the pilot earlier in her term (CBC News 2019).

There was resistance to the pilot cancellation. Four pilot beneficiaries brought a lawsuit to the Ontario Superior Court to demand an upholding of the pilot program, but in February 2019 the court ruled against the

${ }^{1}$ CEOs for Basic Income. https://ceosforbasicincome.ca/. 
plaintiffs, arguing that political decisions could only be taken by the government. An NDP demand to have the Liberal-led federal government continue to fund the pilot was rebuffed by the federal government (Lindeman 2019). A similar petition for federal funding had been launched on the Green Party website. ${ }^{2}$ One of the recipients, Jessie Golem, a photographer, started a photo project capturing other pilot recipients holding signs telling viewers how the basic income has helped them. ${ }^{3}$

\section{Lessons Learned from Canadian Basic Income Experiments}

The relevant questions for Canadian basic income advocates are whether basic income experiments and quasi-experiments are a viable strategy (and in what circumstances) for placing basic income on the decision agenda and how the design and conduct of experiments can be modified to increase the likelihood that a basic income might become the adopted alternative once an experiment is completed. The following lessons might help policy advocates to answer these questions.

A first lesson relates to the risk that cancellation may occur as governments change or new conditions become prominent in the problem stream. This may be a hard risk to prevent completely, because an experiment is much easier to cancel than an established program. However, some actions might be taken to mitigate this risk, at least partially (Mulvale and Frankel 2019). One is to attempt to remove the experiment as much as possible from a narrow partisan framing. This could involve advocates in consulting with all political parties when designing experiments to propose in order to try to incorporate features and research questions of interest to each party. The hope is to insulate the proposal against political change by building a stake in it for each party. Another ameliorative action could involve softening the environment for introduction of a basic income experiment early in a government's mandate so that it is completed or almost completed before the next election. Beyond this, developing broad support from civil society organizations and the public might make it difficult, but not impossible, to cancel experiments.

A second lesson relates to the threats to construct validity in timelimited basic income experiments. Mendelson (2019) points out that

\footnotetext{
${ }^{2}$ Green Party of Canada. https://www.greenparty.ca/en/save-basic-income-pilot.

${ }^{3}$ Jessie Golem Website. https://www.jessiegolem.com/humans-of-basic-income/.
} 
these are inherent in basic income experiments in which participants may be responding to the short-term nature of the program differently than they would to a permanent program, and Simpson et al. (2017) point out that the direction of the differences may be unpredictable. In addition, participants may be responding to the experimental measurement arrangements, to frequent monitoring or to the contrast between their experience and that of non-participants in their neighborhoods or networks, rather than to the basic income intervention. Some of these effects might be reduced through using administrative data supplemented by survey or interview data (Simpson et al. 2017). Including various lengths of the guarantee period in experiments may help to estimate the effects of the short-term nature of experiments. However, the threats to construct validity can never be eliminated completely.

Since policy advocates are interested in the use of the experimental findings as a persuasive tool, it is important for them to determine how bureaucratic and political decision makers understand and appraise these threats to construct validity. Do they understand the nature and effect of these threats? Do they feel that experimental findings are still useful despite these threats? The answers to these questions will help determine whether experiments are a useful strategy for moving basic income onto the agenda.

A third and similar lesson involves threats to external validity related to selection bias, when selected participants with particular characteristics cannot be recruited into the experiment and non-random attrition bias, when those with particular characteristics are over-represented in participants who leave the experiment (Mendelson 2019; Simpson et al. 2017). These threats render the experimental sample as unrepresentative of the relevant population that would be served by a basic income. Attrition bias can be partially reduced by using administrative data to follow participants who leave, but many threats to external validity will remain. Again, it is important that advocates assess how decision makers understand and evaluate these threats.

A fourth lesson involves the benefit of including a saturation site, like the one in Dauphin, so that local community-level and local economylevel effects can be studied (Mendelson 2019). For example, it would be useful for advocates to know if basic income enhances norms of social solidarity and trust as some suggest (Standing 2008). This may decrease community violence and increase social support, which might constitute good evidence for advocacy. However, saturation sites can also produce 
findings that are difficult for basic income advocates to manage, and they must arm themselves with strategies to deal with this. For example, Calnitsky and Latner (2017) found, in a comparative analysis of Dauphin saturation participants and a rural dispersed sample, that Dauphin participants experienced a $3.2 \%$ decline in labor market participation due to a community context effect that was beyond what dispersed participants experienced.

A fifth lesson is that advocates should concern themselves with insuring that political decision makers receive some political payoff as early as possible in the conduct of the experiment. This might be accomplished through early release of preliminary findings, which was not done in the case of Mincome. This may have contributed to limitations in political commitment (Simpson et al. 2017). It may also have limited the opportunity to develop public support for the experiment. Release of preliminary findings must be accompanied by a carefully constructed communication plan, especially in relation to findings that might be construed as negative (Widerquist 2005). Also, care must be taken to monitor any reactivity in program participants based on the release of preliminary findings.

\section{Possible Approaches for Future Advocacy}

In addition to the lessons from the multiple streams framework analysis and basic income experiments, several other advocacy approaches might be considered.

One approach would involve basic income advocates presenting analyses critical of one of the leading alternative policies, social assistance (Segal 2012). Emphasis might be placed on high administrative costs related to selective eligibility assessment, monitoring for compliance with conditions and enforcement (Forget 2018). In addition, the stigmatizing effects of last resort social assistance might be highlighted (Calnitsky 2016), along with the negative health effects produced by stigma (Link and Phelan 2006; Reuter et al. 2009). In turn, these effects can significantly increase healthcare costs (Sharac et al. 2010). Usefully, in an analysis based on 407 community experience surveys completed by Dauphin saturation site basic income recipients, Calnitsky (2016) found that recipients did not report subjective feelings of stigma and their levels of community involvement indicated that they did not occupy stigmatized social roles.

Another approach relates to the cost of a proposed basic income. This is significantly dependent on the guarantee level. As described above, this 
is one of the key issues raised by opponents of basic income. Forget's (2011) research demonstrates that a benefit well below the poverty line can produce positive health and educational effects. This may support a foot in the door advocacy approach in which a basic income with a low guarantee is first implemented, and then, attention is turned to increasing the guarantee level (Mulvale and Frankel 2019).

In detail, in Dauphin, the maximum guarantee was only $60 \%$ of the Low Income Cut-Offs, a semi-relative poverty measure often used to calculate poverty statistics in Canada (Forget 2011). Statistics Canada (2015) describes the Low Income Cut-Offs as "income thresholds below which a family will likely devote a larger share of its income on the necessities of food, shelter and clothing than the average family." This maximum benefit amounted to $\$ 3,800$ (1974 dollars) for a family of two adults and two children under 15 (Simpson et al. 2017). This was approximately $38 \%$ of median family income (Calnitsky 2016).

\section{CONCLUSION}

This chapter began by using the Multiple Streams Approach to analyze basic income advocacy in Canada and to make recommendations to enhance its effectiveness. Then, basic income experiments were examined as a basic income advocacy strategy. Finally, approaches were suggested related to the cost of basic income and displaying its superiority to social assistance.

Basic income has entered the primeval soup of the policy stream, but has not yet been successfully linked with a policy problem prominent enough in the problem stream to be on the decision agenda. Basic income advocates must make careful strategic choices about linking to a range of problems which have good potential to enter the decision agenda, and affect a large enough portion of the public. They must find the balance between a range of linkable problems large enough to attract sufficient public support, but small enough to allow the construction of coherent policy networks and communities. The problems must also be in the jurisdiction of a limited and complementary set of government decision makers.

One potential approach is to construct social assistance as a problem (rather than a policy solution) and to link it to basic income as a better alternative. Beyond this, the basic income policy community can increase the likelihood of emerging from the policy soup by developing a broadly 
consensual definition of basic income and, ideally, by developing a specific proposal with broad support. There is evidence that a less costly proposal can produce useful outcomes and act as a foot in the door.

Experimentation should only be considered if there is broad cross-party support and an inclination among decision makers to consider experimental evidence valuable despite limitations in construct and external validity. In addition, the experimental plan must include releasing findings to engender political payoffs as early as possible in the experimental process.

There are some hopeful signs, including the emergence of two strong civil society organizations, Basic Income Canada Network and UBI Works, both significantly focused on generating public support. UBI Works is connected to entrepreneurial resources, and an important tactic is to grow the resource base of the Basic Income Canada Network. Another hopeful sign is the emergence of new policy entrepreneurs.

\section{REFERENCES}

Basic Income Canada Network. 2019a. "Signposts to Success: Report of a BICN Survey of Ontario Basic Income Recipients." https://assets. nationbuilder.com/bicn/pages/42/attachments/original/1551664357/ BICN_-_Signposts_to_Success.pdf.

Basic Income Canada Network. 2019b. "Annual Report 2018/2019.” https:// drive.google.com/file/d/1EEwyhM4iOk8DoYFLRQNvKXhM_530492j/ view.

Béland, Daniel, and Michael Howlett. 2016. "The Role and Impact of the Multiple-Streams Approach in Comparative Policy Analysis." Journal of Comparative Policy Analysis: Research and Practice 18 (3, May 26): 221-227. http://www.tandfonline.com/doi/abs/10.1080/13876988.2016.1174410.

Boadway, Robin, Katherine Cuff, and Kourtney Koebel. 2016. "Designing a Basic Income Guarantee for Canada." IDEAS Working Paper Series from RePEc, January 1. http://search.proquest.com/docview/2083047056/.

Boessenkool, Ken. 2020. "In Normal Times, Universal Basic Income Is a Bad Idea. But It's the Wisest Solution for COVID-19 Economic Strain." Globe and Mail, March. https://www.theglobeandmail.com/opinion/article-innormal-times-universal-basic-income-is-a-bad-idea-but-its-the/?utm_source= Shared+Article+Sent+to+User\&utm_medium $=$ E-mail:+Newsletters $+/+$ EBlasts+/+etc.\&utm_campaign=Shared+Web+Article+Links.

Calnitsky, David. 2016. “More Normal Than Welfare': The Mincome Experiment, Stigma, and Community Experience." Canadian Review of Sociology/Revue canadienne de sociologie 53 (1, February): 26-71. 
Calnitsky, David, and Jonathan P. Latner. 2017. "Basic Income in a Small Town: Understanding the Elusive Effects on Work." Social Problems 64 (3, August): 373-397.

Canadian Centre for Economic Analysis. 2019. "Economic Contribution of the Canada Child Benefit: A Basic Income for Canadian Families with Children." Downloaded from https://www.cancea.ca/sites/economic-analysis.ca/files / Economic\%20Contribution\%20of\%20the\%20Canada\%20Child\%20Benefit $\%$ 20-\%20Final\%20-\%2020190916.pdf.

Caputo, Richard. 2014. Policy Analysis for Social Workers. Thousand Oaks, CA: Sage.

Canada, 2018. Opportunity for All: Canada's First Poverty Reduction Strategy. Gatineau, QC: Employment and Social Development Canada = Emploi et développement social Canada.

CBC News. 2018. “Ontario Minister Admits Ford Government Broke Election Promise by Scrapping Basic Income Project," August 2.

CBC News. 2019. “They Don't Have a Plan'-Kathleen Wynne Criticizes Ford Government Over Basic Income,” April 1. https://www.cbc.ca/news/ canada/hamilton/wynne-basic-income-1.5079754.

Clavet, Nicholas-James, Jean-Yves Duclos, and Guy Lacroix. 2012. Fighting Poverty Assessing the Effect of a Guaranteed Minimum Income Proposals in Québec Montréal. Que: Center for Interuniversity Research and Analysis on Organizations.

Cohen, Michael D., James G. March, and Johan P. Olsen. 1972. "A Garbage Can Model of Organizational Choice." Administrative Science Quarterly: 1-25.

Duclos, Jean-Yves. 2007. “A Better Income Security System for All Canadians." In A Canadian Priorities Agenda: Policy Choices to Improve Economic and Social Wellbeing, edited by Jeremy Leonard, Christopher Ragan and France St. Hilaire, 233-266. Montreal: Institute for Research on Public Policy.

Eggelton, Art and Segal Hugh. 2020. "Eggleton and Segal: COVID-19 Presents Lessons in How a Guaranteed Basic Income Program Could Work."

Ottawa Citizen, April. https://ottawacitizen.com/opinion/eggleton-andsegal-covid-19-presents-lessons-in-how-a-guaranteed-basic-income-programcould-work/wcm/dcfde233-c628-4589-8465-d334f7cd579b/.

Ferdosi, Mohammad, McDowell Tom, Lewchuk Wayne, and Ross Stephanie. 2020. "Southern Ontario's Basic Income Experience." https://labourstudies. mcmaster.ca/documents/southern-ontarios-basic-income-experience.pdf.

Forget, Evelyn L. 2011. "The Town with No Poverty: The Health Effects of a Canadian Guaranteed Annual Income Field Experiment." Canadian Public Policy/Analyse de Politiques 37 (3, September 1): 283-305. http://search. proquest.com/docview/101.

Forget, Evelyn L. 2018. Basic Income for Canadians: The Key to a Healthier, Happier, More Secure Life for All. Toronto: James Lorimer \& Company Ltd. 
Forget, Evelyn L., and Hugh Segal. 2020. "Canada's Emergency Response Benefit Is an Unintended Experiment in Basic Income; OPINION." Globe and Mail. Toronto, Ontario: CNW Group Ltd., April 20. https://search. proquest.com/docview/2392316399.

Frankel, Sid. 2020. "Universal Basic Income Offers Stability During Crisis." Winnipeg Free Press, March 27. Accessed April 30, 2020. https://search-proquestcom.uml.idm.oclc.org/docview $/ 2383318620$ ? accountid=14569.

Frankel, Sid., and James Mulvale. 2014. "Support and Inclusion for All Manitobans: Steps Toward a Basic Income Scheme." Manitoba Law Journal 37 (2): 425-464.

Fraser, Mark W, and Maeda J. Galinsky. 2010. "Steps in Intervention Research: Designing and Developing Social Programs." Research on Social Work Practice 20 (5, September): 459-466.

Green, David A, W. Craig Riddell, and France St-Hilaire. 2017. Volume V Income Inequality: The Canadian Story. Montreal, QC: Institute for Research on Public Policy.

Hamilton, Leah, and James P. Mulvale. 2019. “'Human Again': The (Unrealized) Promise of Basic Income in Ontario." Journal of Poverty 23 (7): 1-24.

Henstra, Daniel. 2010. "Explaining Local Policy Choices: A Multiple Streams Analysis of Municipal Emergency Management." Canadian Public Administration 53 (2): 241-258.

Herweg, Nicole, and Nikolaos Zahariadis. 2017. "The Multiple Streams Approach." In The Routledge Handbook of European Public Policy, edited by Nikolaos Zahariadis and Laurie Buonanno, 32-41. London: Routledge.

Hum, Derek, and Wayne Simpson. 1993. "Economic Response to a Guaranteed Annual Income: Experience from Canada and the United States." Journal of Labor Economics 11 (1, January 1): S263-S296.

Ipsos. 2017. "Public Perspectives." Downloaded from https://www.ipsos.com/ sites/default/files/2017-06/public-perspectives-basic-universal-income2017-06-13-v2.pdf.

John, Peter. 1998. Analyzing Public Policy. London: Routledge (October 1, 2019).

Kaplan, Jerry. 2015. Humans Need Not Apply: A Guide to Wealth and Work in the Age of Artificial Intelligence. New Haven, CN: Yale University Press.

Kesselman, Jonathan. 2014. "A Dubious Antipoverty Strategy." Inroads 34 (January 1): 33-43. http://search.proquest.com/docview/1468872819/.

Kingdon, John W. 2011. Agendas, Alternatives, and Public Policies. Updated 2nd ed. Boston: Longman.

Lewchuk, Wayne. 2018. "Chapter Four: Changing Job Markets: Working without a Net." In Thee Poverty, Inequality, and Job Challenge: The Case for Basic Income in Canada, edited by Roderick Benns and Joli Scheidler-Benns, 3344. Lindsay: Fireside Publishing House. 
Liberal Party of Canada. 2014. "Adopted Resolutions: Biennial Convention. Montreal 2014. \#100: Creating a Basic Annual Income to be Designed and Implemented for a Fair Economy," p. 17. Accessed, October 1, 2019. https://www.liberal.ca/wp-content/uploads/2010/05/ Priority-Resolutions-EN-FINAL.pdf.

Liberal Party of Canada. 2016. "Adopted Priority Resolutions, Biennial Convention, Winnipeg 2016. Poverty Reduction: Minimum Income.” Accessed October 1, 2019. https://www.liberal.ca/wp-content/uploads/2017/07/ Adopted-PRIORITY-Resolutions-Biennial-2016-EN.pdf.

Liberal Party of Canada. 2018. "Implementation of a Guaranteed Minimum Income Model. Policy Resolution 11.” Accessed October 1, 2019. https:// 2018.liberal.ca/policy/implementation-of-a-guaranteed-minimum-incomemodel/.

Lindeman, Tracey. 2019. “A Lawsuit to Save Ontario's Basic Income Program Has Failed.” Canada's National Observer, February 15. https:// www.nationalobserver.com/2019/02/15/news/lawsuit-save-ontarios-basicincome-program-has-failed.

Link, Bruce G, and Jo C. Phelan. 2006. "Stigma and Its Public Health Implications." The Lancet 367 (9509, February 11): 528-529.

Marston, Greg. 2016. "Greening the Australian Welfare State: Can Basic Income Play a Role?" In Basic Income in Australia and New Zealand, 157-177. New York: Palgrave Macmillan.

Mclaughlin, Milbrey. 1987. "Learning from Experience: Lessons from Policy Implementation." Educational Evaluation and Policy Analysis 9 (2): 171178.

Mendelson, Michael. 2019. Lessons from Ontario's Basic Income Pilot. Toronto: Maytree, 2019. https://deslibris.ca/ID/10102735.

Mulvale, James P., and Sid Frankel. 2016. "Next Steps on the Road to Basic Income in Canada." Journal of Sociology \& Social Welfare 43 (3, September 1): $27-50$.

Mulvale, James P., and Sid Frankel. 2019. "Basic Income in Canada: Lessons Learned and Challenges Ahead." In Implementing a Basic Income in Australia, edited by Elsie Klein, Jennifer Mays, and Tim Dunlop, 237-257. Cham: Palgrave Macmillan.

Murray, Matthew C., and Carole Pateman. 2012. Basic Income Worldwide: Horizons of Reform Houndmills. Basingstoke, Hampshire: Palgrave Macmillan.

National Academies of Sciences, Engineering, and Medicine. 2019. A Roadmap to Reducing Child Poverty. Washington, DC: The National Academies Press. https://doi.org/10.17226/25246.

Offe, Claus. 2001. "+Pathways from here”. In What's Wrong with a Free Lunch?, edited by Phillipe Van Parijs, 111-118. Boston: Beacon Press. 
Ontario. 2017. Ontario Basic Income Pilot. Toronto, ON: Government of Ontario. Accessed October 2, 2019. https://www.ontario.ca/page/ontariobasic-income-pilot.

Opportunity knocks for basic income backers: As Ottawa hands out \$2,000 emergency cheques to people forced out of work, experts say the pandemic may provide a golden moment to mend gaps in the Canadian social safety net. 2020. Toronto Star, April 25, 2020. Accessed April 30, 2020. https://searchproquest-com.uml.idm.oclc.org/docview/2394521609? accountid=14569.

Pereira, Richard. 2017. "The Cost of Universal Basic Income: Public Savings and Programme Redundancy Exceed Cost". In Financing Basic Income, edited by Richard Pereira, 9-45. New York, NY: Palgrave Macmillan.

Press, Jordan. 2018 "Liberals Say They Are Looking at Ways to Provide Minimum Income to All Canadians." National Post, December. https://nationalpost.com/news/canada/liberals-say-they-are-looking-atways-to-provide-minimum-income-to-all-canadians.

Rawat, Pragati, and John Charles Morris. 2016. “Kingdon's 'Streams' Model at Thirty: Still Relevant in the 21st Century?" Politics \& Policy 44 (4): 608-638. https://doi.org/10.1111/polp.12168.

Reinhart, R. J. 2019. "Universal Basic Income Favored in Canada, U.K. but Not in U.S." Gallup News Service, September. https://news.gallup.com/ poll/267143/universal-basic-income-favored-canada-not.aspx.

Reutter, Linda I., Miriam J. Stewart, Gerry Veenstra, Rhonda Love, Dennis Raphael, and Edward Makwarimba. 2009. "Who Do They Think We Are, Anyway?': Perceptions of and Responses to Poverty Stigma." Qualitative Health Research 19 (3, March): 297-311.

Robson, Jennifer. 2018. "Is the Liberals' Federal Poverty-Reduction Strategy Even Really a Strategy?" Macleans, August 21. https://www.macleans.ca/ opinion/is-the-liberals-federal-poverty-reduction-strategy-really-a-strategy/.

Segal, Hugh. 2012. "Scrapping Welfare." Literary Review of Canada 20 (10, December 1). http://search.proquest.com/docview/1242314398/.

Segal, Hugh. 2016. "Finding a Better Way: A Basic Income Pilot Project for Ontario." Government of Ontario, August 31. https://www.ontario.ca/ page/finding-better-way-basic-income-pilot-project-ontario\#section-8.

Segal, Hugh. 2019. Bootstraps Need Boots: One Tory's Lonely Fight to End Poverty in Canada. Vancouver, BC: On Point Press, a UBC Press Imprint.

Shadish, William R., Thomas D. Cook, and Donald T. Campbell. 2002. Experimental and Quasi-Experimental Designs for Generalized Causal Inference. Boston: Houghton Mifflin.

Sharac, Jessica, Paul Mccrone, Sarah Clement, Graham Thornicroft, and Jessica Sharac. 2010. "The Economic Impact of Mental Health Stigma and Discrimination: A Systematic Review." Epidemiologia e psichiatria sociale 19 (3, July 1): 223-232. http://search.proquest.com/docview/847432648/. 
Simpson, Wayne, Greg Mason, and Ryan Godwin. 2017. "The Manitoba Basic Annual Income Experiment: Lessons Learned 40 Years Later." Canadian Public Policy 43 (1, March 1): 85-104. http://search.proquest.com/docview/ $1877367439 /$.

Smith, Verna. 2018. Bargaining Power Health Policymaking from England and New Zealand. 1st ed. Singapore: Springer Singapore.

Smith-Carrier, Tracy A., and Steven Green. 2017. "Another Low Road to Basic Income? Mapping a Pragmatic Model for Adopting a Basic Income in Canada." Basic Income Studies 12 (2, September 19): 1-25.

Standing, Guy. 2008. "How Cash Transfers Promote Basic Income." Basic Income Studies 3 (1): 1-30.

Statistics Canada. 2015. Low Income Lines, 2011-2012. https://deslibris.ca/ ID $/ 238559$.

Thurber, James A. 2011. Foreword to Agendas, Alternatives, and Public Policies. Updated 2nd ed. By John W. Kingdon, vii-xi. Boston: Sage.

Tweddle, Anne, and Hannah Aldridge. 2019. Welfare in Canada, 2018. Toronto: Maytree.

UBI Works. n.d. "The team, What we do." Accessed October 21 2019. https:// ubiworks.ca/.

Van Parijs, Philippe. 2004. "Basic Income: A Simple and Powerful Idea for the Twenty-First Century." Politics \& Society 32 (1, March): 7-39.

Widerquist, Karl. 2005. "A Failure to Communicate: What (if Anything) Can We Learn from the Negative Income Tax Experiments?" Journal of SocioEconomics 34 (1): 49-81.

Wright, Teresa. 2020. "Trudeau Rejects Turning CERB's $\$ 2,000$ a Month Into a Universal Benefit for Canadians." April. https://nationalpost.com/news/ universal-benefit-minimum-basic-income-justin-trudeau-cerb.

Zahariadis, Nikolaos. 2019. "The Multiple Streams Framework: Structure, Limitations, Prospects." In Theories of the Policy Process, 2nd ed., edited by Paul A. Sabatier, 65-92. New York: Routledge. 